\title{
Who Gives a Damn about Minimizers in Questions?
}

\author{
Klaus Abels \\ University of Connecticut/Universität Leipzig
}

\section{Background and a puzzle}

Klima (1964) described the distribution of Negative Polarity Items (any, ever, lift a finger, give a damn, ...) in terms of two diacritics: [+/-affective], characterizing (non-)licensing environments, and [+/- NPI], characterizing the items themselves. Ladusaw (1980) argued that [+affective] is a semantic property, not a diacritic: all NPI-licensing contexts are Downward Entailing (DE) - and possibly must meet further conditions as well (see also Heim 1984; Linebarger 1980; Progovac 1993; von Fintel 1999). Later Chierchia (2000), Kadmon and Landman (1993), Krifka (1994), Lahiri (1998), Lee and Horn (1995), and van Rooy (2002) claimed that [NPI] is not a diacritic either but a semantic property which, moreover, explains the role of DE-ness in NPI licensing. Heim (1984) and von Fintel (1999) refine the DE-ness property to cover some prima facie counterexamples to Ladusaw's generalization.

Interrogatives are an embarrassment to this line of research, since they license NPIs but are not DE and do not fall under the modified concepts of DEness either as is well known (Ladusaw 1980; Linebarger 1980; Progovac 1993).

This paper concentrates on a particular class of NPIs, the Minimizers. Minimizers like lift a finger, give a damn, etc. are have substantially different properties from other NPIs like ever, any, etc. One of the differences is illustrated below. Regular NPIs are licit in questions and are compatible with un-biased, information seeking readings as shown in (1) (see Guerzoni 2002; Han and Siegel 1996). Minimizers are also possible in interrogatives, but give rise obligatorily to rhetorical readings (Guerzoni 2002). Thus (2a) strongly suggests that Peter doesn't care about the environment at all, and (2b) likewise suggests that nobody cares about the environment at all.

a. Has Peter done any wrong?

b. Who has done any wrong here?

a. Does Peter give a damn about the environment?

b. Who gives a damn about the environment?

The aim of the present paper is to demonstrate that a proper lexical semantics for Minimizers together with certain non-standard assumptions about focal alternatives explains why Minimizers are possible in interrogatives in the first place and why they give rise obligatorily to rhetorical readings. Importantly, the Minimizers in (2) pattern with expressions that are transparently composed of a lower endpoint of a scale in combination with even as in (3) on the next page. The slightest bit denotes the lower endpoint on the scale of amounts. These expressions denoting scalar endpoints plus even also force rhetorical readings in 
questions, and in general they have a distribution that is very similar to that of Minimizers (Heim 1984).

a. Does Peter care even the slightest bit about the environment?

b. Who cares even the slightest bit about the environment?

The fact that Minimizers pattern with expressions that denote lower endpoints of a scale plus even and against regular NPIs is not surprising if we treat Minimizers, but not regular NPIs, as semantically equivalent to expressions denoting lower endpoints of a scale + even (see Guerzoni 2002; Heim 1984; Krifka 1995; Lahiri 1998). These authors offer independent motivation for this treatment that I cannot review here. I will follow them and assume a lexical semantics for Minimizers where they denote lower endpoints of a scale plus even.

While the kind of pattern observed in (1)-(3) is then unsurprising, Lahiri (1998) and Wilkinson (1996) note that standard treatments of even predict neither that (2) and (3) are acceptable nor why such questions obligatorily get a rhetorical reading.

In section 2 , I briefly introduce my assumptions about even, which deviate slightly from the standard lexical semantics as given for example in Wilkinson 1996. 'In section $3 \mathrm{I}$ argue that the set of focus alternatives evoked by even is crucially larger than generally assumed. Section 4 explores the consequences of broadening the set of alternatives in this way and show how the judgments concerning (2) and (3) follow from these assumptions. Section 5 discusses some further independent support for broadening the set of focus alternatives. Section 6 concludes the paper.

\section{On even}

It is commonly assumed that even has a lexical entry along the lines given in (4) (see e.g. Wilkinson 1996).

$$
\begin{aligned}
& \llbracket \text { even }_{\mathrm{C}} \rrbracket=\lambda \mathrm{p}_{<\mathrm{s}, \mathrm{b}} \lambda \mathrm{w}_{<\mathrm{s}>} \text { : } \\
& \exists \mathrm{q}_{<\mathrm{s}, \mathrm{b}}[\mathrm{q} \in \mathrm{C} \& \mathrm{q} \neq \mathrm{p} \& \mathrm{q}(\mathrm{w})] \text {. } \\
& \mathrm{p}(\mathrm{w})
\end{aligned}
$$

Scalar Presupposition Existential Presupposition

Assertion

Here even is truth-functionally inert. It is the identity function from propositions to propositions ((4iii)). Even contributes two presuppositions, however. It contributes a scalar presupposition, (4i), according to which the asserted proposition $\mathrm{p}$ is the least likely of all alternative propositions $\mathrm{q}$ from a contextually supplied set of alternatives, C. Even also contributes an existential presupposition, (4ii), according to which one of the alternative propositions in the contextually given set $\mathrm{C}$ must be true. The variable $\mathrm{C}$, a set of propositions, is an implicit contextual variable. 
Before exemplifying (4), consider (5). The lexical entry in (5) is logically equivalent to that in (4), but it brings out the double function of the Existential Presupposition. The Existential Presupposition in (4) says that the set of contextual alternatives must be non-trivial (5ii) and that it must contain a true alternative to the asserted proposition (5iii).

(5) $\quad \llbracket e v e n_{C} \rrbracket=\lambda p_{<s, \triangleright} \lambda w_{<s>}$ :

(i) $\quad \forall \mathrm{q}_{<s, \triangleright}\left[[\mathrm{q} \in \mathrm{C} \& \mathrm{q} \neq \mathrm{p}] \rightarrow \mathrm{q}>_{\text {likely }} \mathrm{p}\right] \& \quad$ Scalar presupposition

(ii) $\quad \exists q_{<s, \triangleright}[q \in C \& q \neq p] \& \quad$ Notriviality of $C$

(iii) $\quad \exists q_{<s, \triangleright}[q \in C \& q \neq p \& q(w)]$. Existence of true alternative $\mathrm{p}(\mathrm{w})$

Assertion

We now turn to example (6) to illustrate how (4/5) works.

(6) John has solved even the hardest problem.

According to (4/5), example (6) asserts that John solved the hardest problem ((5iv)) and presupposes ((5i)) that the hardest problem was the least likely one for John to solve, ((5ii)) that there is at least one other problem under discussion, (5iii) that John solved at least one of the other problems under discussion.

Suppose there are nine problems (problem \#1-\#9), problem \#9 being the hardest. Example (6) should thus be felicitous if John solved problems \#1, \#9, and no other problem. This is false. Example (6) is only felicitous if John solved all relevant problems including the hardest one. It is not sufficient that he solved just one of the relevant problems. Rather, he must have solved all of them (see for relevant discussion and possible further refinements Kay 1990; van Rooy 2002). We can implement this by making (5iii) presuppose the truth of all (relevant) alternatives as in (7iii). ${ }^{2}$

$$
\begin{aligned}
& \llbracket \text { even }_{\mathrm{C}} \rrbracket=\lambda \mathrm{p}_{<\mathrm{s}, \triangleright} \lambda \mathrm{w}_{<\mathrm{s}>}: \\
& \forall \mathrm{q}_{<\mathrm{s}, \mathrm{\Delta}}\left[[\mathrm{q} \in \mathrm{C} \& \mathrm{q} \neq \mathrm{p}] \rightarrow \mathrm{q}>_{\text {likely }} \mathrm{p}\right] \& \\
& \exists \mathrm{q}_{\mathrm{ss}, \triangleright}[\mathrm{q} \in \mathrm{C} \& \mathrm{q} \neq \mathrm{p}] \& \\
& \forall \mathrm{q}_{<\mathrm{s}, \triangleright}[[\mathrm{q} \in \mathrm{C} \& \mathrm{q} \neq \mathrm{p}] \rightarrow \mathrm{q}(\mathrm{w})] \\
& \mathrm{p}(\mathrm{w})
\end{aligned}
$$

Scalar presupposition Notriviality of $\mathrm{C}$ Truth of all alternatives Assertion

The remainder of the paper is based on (7) as the lexical entry for even. I will assume that in this form even is a semantic component of the Minimizers.

\section{Introducing an additional alternative}

In both of the lexical entries for even discussed in the previous section, the contextual restriction on even, the variable $\mathrm{C}$, remained implicit. It is not syntactically realized independently. When hearing a sentence with even or a Minimizer, cooperative hearers construct a suitable value for $\mathrm{C}$ that will make the utterance maximally relevant, coherent, informative, etc. This process is 
independently needed for example to account for the fact that quantifiers are contextually restricted and to generate a non-contradictory reading in examples like (8).

(8) Everybodyc's computer is faster than John's.

Without a suitable contextual restriction on everybody, sentence (8) would entail the contradiction that John's computer is faster than itself. C must be restricted somehow to avoid this.

Assume for concreteness that $\mathrm{C}$ is a subset of the focus semantic value of the LF-sister of even - even associates obligatorily with focus. A familiar Roothian (Rooth 1992) way of implementing this is given in (9). ${ }^{3}$

(9) Let $\alpha$ be the sister of even at LF,

$\llbracket \alpha \rrbracket^{f}$ be the focus semantic value of $\alpha$, and

$\mathrm{C}$ the contextual restriction on even, then $C \subseteq \llbracket \alpha \rrbracket^{f}$.

In the case at hand, $[\alpha \rrbracket$ denotes a proposition, because even is a partial function from a proposition to a proposition (type $<<$ s, $t>,<$ s, $t>>$ ). Therefore $\llbracket \alpha \rrbracket^{f}$ denotes a set of propositions, the denotation of a question. I suggest modifying (9) in one crucial respect and to use (10) instead.

(10) Let $\alpha$ be the sister of even at LF,

$\llbracket \alpha \rrbracket^{\mathrm{f}}$ be the focus semantic value of $\alpha$,

$\mathrm{C}$ the contextual restriction on even, and

$W$ the set of possible worlds, then $\mathrm{C} \subseteq\left(\llbracket \alpha \rrbracket^{\mathrm{f}} \cup\left\{\mathbf{W}-\cup[\alpha]^{\mathrm{f}}\right\}\right)$.

The set of propositions in (10) from which $C$ may be constructed is crucially a proper superset of the set from which $\mathrm{C}$ may be constructed according to (9) The set in (10) includes all the usual focus alternatives to $\llbracket \propto$ and also the negation of their disjunction, i.e. the proposition that all focus alternatives are simultaneously false. I will call the Negation Of the Disjunction of focal alternatives, i.e. $\left\{\mathrm{W}-\cup[\alpha]^{\mathrm{f}}\right\}$, NOD in what follows. The consequence of assuming (10) in an example like (6) above is that all propositions of the form that John solved problem \#n and the proposition that John solved no problem may be considered in constructing $\mathrm{C}$.

\subsection{Defending (10)}

(10) looks fairly ad hoc at first. I will show in section 4 how assuming (10), i.e. potentially including NOD in C, accounts for the rhetorical effect. First I will illustrate though that NOD plays a role elsewhere in the grammar as for example in interrogatives and in focus constructions without even. The claim is that if $\mathrm{P}$ is 
a set of propositions, it is quite common that $\mathrm{W}-\cup \mathrm{P}$ plays a linguistically significant role.

A first indication that this claim may be correct, comes from the following remark that Karttunen (1977:18 ft. 11) makes: "John knows whether Mary cooks or Bill eats out [is] true just in case John knows every proposition in the set denoted by whether Mary cooks or Bill eats out provided that the set is nonempty, and in the event it is, just in case John knows that it is empty, i.e. knows that Mary doesn't cook and Bill doesn't eat out". According to Karttunen, for John to know Q, Q a set of propositions (Hamblin 1973), John has to know which member(s) of the set $\mathrm{Q} \cup\{\mathrm{W}-\cup \mathrm{Q}\}$ is/are true. John has to know which members of the Hamblin denotation of a question are true or he has to know that NOD is true.

It is sometimes suggested that NOD $(\mathrm{W}-\cup \mathrm{Q})$ is a possible but not an altogether regular rejoinder to a $w h$-interrogative. Note that NOD involves the negative quantifier nobody in place of the wh-word. The implicit assumption is that if nobody is licit in place of the wh-word, then other quantifiers should be as well. That this is not the case is shown in (11), which can easily be answered by asserting NOD ((11a)), but using quantifiers other than nobody in the answer gives odd results $((11 b)$ and (11c)).
A: Who came?
a. B: $\checkmark$ Nobody did.
b. B: \# Some people did.
c. B: \# More than three people did.

Especially examples like (11c) could potentially be used to motivate the claim that answers with quantifiers are not members of the question set per se. This was, of course, Hamblin's original position. Such a ban against quantifiers in place of wh-words would also rule out (11b), but it incorrectly rules out (11a) as well. It would then have to be true that (11a) is indeed ruled out as a regular answer to the question, and that in (11a) an existential presupposition of the question is rejected. ${ }^{4}$ NOD would then not be an answer to the question but a presupposition rejecting rejoinder.

The question then arises whether (11a), i.e. NOD, patterns with regular answers or whether it patterns with rejoinders to questions that clearly reject presuppositions of questions. In fact, NOD patterns with regular answers.

Consider example (12) on the following page, where the presence of why introduces the presupposition you ate an apple. Rejecting this presupposition must be specially marked either in terms of intonation (12b)-(12c) or by lexical means (12d). Rejecting the presupposition is impossible without such marking (12a). Moreover, when the presupposition is not rejected (12e)-(12h), the special marking is impossible. 
(12) A: Why did you eat an apple?

a. B: \# I didn't eat an(y) apple.

b. B: $\checkmark$ I didn't EAT an(y) apple.

c. B: $\mathscr{J}$ I DIDN'T eat an(y) apple.

d. B: $\checkmark$ But I didn't eat an(y) apple.

e. B: $\checkmark$ I didn't do it for any particular reason.

f. B: \# I didn't DO it for any particular reason

g. B: \# I DIDN'T do it for any particular reason

h. B: \# But I didn't do it for any particular reason.

The special devices in (12b)-(12c) are thus used in an answer iff a presupposition of the question is to be rejected. We can therefore use these special devices to diagnose whether an answer rejects a presupposition of a question. In (11a), no such special device is present, or indeed possible ((13)).

(13) Who came?

a. $\checkmark$ Nobody did.

b. \# But nobody did.

c. \# Nobody DID (come).

From this it follows that NOD (W- $\cup$ Q) must be considered an admissible regular answer to a question. It is neither the case that all quantifiers must be treated that way $((11 \mathrm{~b}-\mathrm{c}))$, nor is it the case that NOD rejects a presupposition of the interrogative. The issue of the quantifier in place of the $w h$-word is a red herring.

We can now briefly turn to focus constructions. Consider the polar interrogative in (14) with marked stress on John. In all the answers (14a-d) the question is negated. In (14a) one of the alternatives to John, Mary, is asserted. NOD, the sentence with nobody in (14b), behaves on a par with (14a), sentences with other quantifiers like somebody and most people in (14c) and (14d) do not. Again this suggests that quantifiers do not generally act as alternatives to proper names and that NOD is a licit alternative independently of the quantifier issue.
A: Did JOHN go to the party?
a. B: $\mathcal{J}$ No, MARY did.
b. B: $\checkmark$ No, NOBODY did.
c. B: \# No, SOMEBODY did
d. B: \# No, MOST people did.

From the facts discussed in this subsection I conclude that NOD $\left(\mathrm{W}-\cup \llbracket \alpha \rrbracket^{f}\right.$ ) is involved generally in constructing answers to question and as alternatives in focus constructions. It is then not surprising that we find NOD playing a role in the interpretation of sentences with even as we will see in the next sections. 


\section{The Explanation: Minimizers in Questions}

\subsection{Polar Questions}

We can now return to the initial puzzle: the behavior Minimizers in questions. I will first discuss polar interrogatives like example (2a) repeated here for reference. Crucial properties of the LF of example (2a) are given in the labeled bracketing in (15).

(2) a. Does Peter give a damn about the environment?

(15) $\left[Q_{\text {polar }}\left[\mathrm{XP}\right.\right.$ even $\left[\right.$ Peter cares to the $[\text { minimal }]_{\mathrm{Foc}}$ degree about the environment]]]

Following Hamblin (1973) I assume that polar interrogatives denote two membered sets of propositions $\{\mathrm{p}, \neg \mathrm{p}\}$. The question forming operator for polar

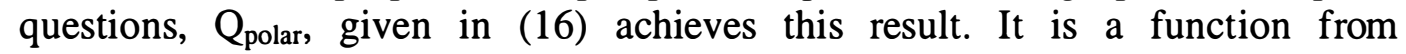
propositions to sets of propositions.

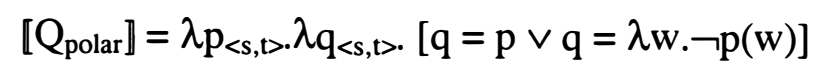

A question arises how presuppositions carried by the sister of the interrogative operator are treated. I assume that the members of the question set each inherit the presuppositions of the proposition expressed in the question. In

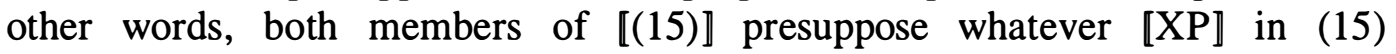
presupposes. [XP】 is a proposition with even, thus it carries the relevant presuppositions. According to the lexical entry of even arrived at in section 2, these are the presuppositions in (17). (17i) says that for Peter to care minimally about the environment is the least likely of the relevant set of alternatives. (17ii) says that the set of alternatives must not be trivial, and (17iii) says that all relevant alternatives in $\mathrm{C}$ must be true.

(i) $\forall \mathrm{q}_{\mathrm{ss}, \mathrm{D}}[[\mathrm{q} \in \mathrm{C} \& \mathrm{q} \neq$ that Peter cares to the minimal degree about the environment] $\rightarrow \mathrm{q}>$ likely that Peter cares to the minimal degree about the environment]

(ii) $\exists \mathrm{q}_{<\mathrm{s}, \triangleright}[\mathrm{q} \in \mathrm{C} \& \mathrm{q} \neq$ that Peter cares to the minimal degree about the environment]

(iii) $\forall \mathrm{q}_{\mathrm{ss}, \triangleright}[[\mathrm{q} \in \mathrm{C} \& \mathrm{q} \neq$ that Peter cares to the minimal degree about the environment $] \rightarrow q(w)]$

This characterization of the interpretation of XP still leaves open the exact value of the contextual variable $C$, the set of alternatives to be considered. We know from (10) above that as a boundary condition $C \subseteq\left(\llbracket X P \rrbracket^{f} \cup\left\{\mathrm{W}-\cup \llbracket X P \rrbracket^{f}\right\}\right)$. Consider now three different possible values for $\mathrm{C}$. 
a. Value 1: $\mathrm{C}=\varnothing$ or $\mathrm{C}=\{\mathrm{p}\}$

b. Value 2: $\mathrm{C}=\{$ that Peter cares to the minimal degree about the environment, that Peter cares to a certain (small) degree about the environment, that Peter cares to a large degree about the environment $\}$

c. Value 3: $\mathrm{C}=\{$ that Peter does not care about the environment; that

Peter cares to the minimal degree about the environment $\}=\left\{\mathrm{W}-\cup \llbracket \mathrm{XP} \rrbracket^{\mathrm{f}}, \mathrm{p}\right\}$

or $\quad \mathrm{C}=\{$ that Peter does not care about the environment $\}=$ $\left\{\mathrm{W}-\cup \llbracket \mathrm{XP} \rrbracket^{\mathrm{f}}\right\}$

Value $1((18 \mathrm{a}))$ is not a possible value for $\mathrm{C}$, because of (17ii), i.e. because any utterance of $(2 a)$ presupposes that the set of alternatives is not trivial.

Value $2((18 b))$ is likewise not a possible value for $\mathrm{C}$. Value 2 is impossible because of (17i), i.e. because of the scalar presupposition of even (see Lahiri 1998). To see this, consider the following where $p$ stands for the proposition that Peter cares to the minimal degree about the environment and $\mathrm{q}$ fore one of the alternatives from $\mathrm{C}$, e.g. that Peter cares to a large degree about the environment. $\mathrm{q}$ entails $\mathrm{p}(\mathrm{q} \rightarrow \mathrm{p}$, i.e. $\mathrm{q} \subseteq \mathrm{p})$ because caring a lot about the environment entails caring to the minimal degree. $p$ on the other hand does not entail q ( $\neg[\mathrm{p} \rightarrow \mathrm{q}]$, or in other words $\mathrm{p} \nsubseteq \mathrm{q})$ because caring to the minimal degree about the environment does not entail caring to a large degree. In other words, $q$ asymmetrically entails $\mathrm{p}(\mathrm{q} \subset \mathrm{p})$. From this it follows that $|\mathrm{q}|<|\mathrm{p}|{ }^{5}$ If as in this case there are less worlds compatible with $q$ than with $p$, then $q$ is less likely than $p$ $(\mathrm{q}<$ likely $\mathrm{p})$. But $(17 \mathrm{i})$ demands on the contrary that $\mathrm{q}>$ likely $\mathrm{p}$.

The same is true for all possible values of $\mathrm{C}$ which include propositions of the form that Peter cares to degree $d$ about the environment, where $d$ is greater than the minimal degree.

Finally, value 3 is in principle possible. It is possible that NOD (that Peter doesn't care about the environment at all) is more likely than $\mathrm{p}$ (that Peter cares to the environment to the minimal degree) ((17i)). If $\mathrm{C}$ is assigned value $3, \mathrm{C}$ is non-trivial ((17ii)). And, according to (17iii) NOD must be true.

The discussion shows that the compositional interpretation of (2a) together with the presuppositions of even force one particular value for $\mathrm{C}$, value 3 . Although generally the value of $\mathrm{C}$ is determined pragmatically, pragmatics has no job to do in this particular case. Consider now how value 3 for $\mathrm{C}$ plays out in the example. Remember that by assumption every member of the question inherits individually the presuppositions of the underlying proposition. The final result of interpreting (15) is shown in (19). Crucially the positive and the negative answers to the question carry the same presuppositions: that Peter doesn't care about the environment and for Peter to care to the minimal degree about the environment is less likely than for him not to care about the environment at all.

$\llbracket(2 \mathrm{a}) \rrbracket=\{$ assert: $\mathrm{p}=$ that Peter cares to the minimal degree about the environment 
presuppose: q=that Peter doesn't care about the environment \& $\mathrm{p}$ is less likely than q;

assert: $\quad \neg \mathrm{p}=$ that Peter doesn't care to the minimal degree about the environment

presuppose: $q=$ that Peter doesn't care about the environment $\mathrm{p}$ is less likely than $\mathrm{q}$

Notice that if the presupposition that Peter doesn't care about the environment is already entailed by the discourse, then the question (2a) is not an open question any more. If we assume that only open questions can be asked felicitously (Roberts 1998), then it should be impossible to ask question (2a) in a context that already entails this presupposition. The presupposition must therefore be introduced by the question. I will assume that a cooperative hearer accommodates the presuppositions carried by a question when admitting it into the discourse. The hearer, we have just seen, always has to accommodate the presupposition 'that Peter doesn't care about the environment' when admitting (2a) into a discourse. The updated context after accommodation entails that Peter doesn't care about the environment at all.

This explains the rhetorical effect. Any utterance of (2a) will force a cooperative hearer to accommodate the presupposition that Peter doesn't care about the environment. What is felt to be the content of the rhetorical question is not actually asserted, it is merely presupposed. The entire process is fully determined since, in particular, the choice of the contextual restriction on even is automatic as discussed above.

In this sense rhetorical questions with Minimizers are on a par with examples where new information is introduced merely as a presupposition. Another example of this type (based on an example in Roberts 1998) is given below as (20). Imagine that the interlocuter does not know that Sam cheated on his wife.

Isn't it shocking that Sam cheated on his wife?

The presupposition of a rhetorical question is insinuated in just the way that (20) insinuates that Sam cheated on his wife. This concludes the discussion of the rhetorical effect for non-negated polar questions.

\subsection{Aside on Declaratives}

A question that arises immediately, is this: What is the impact of allowing NOD to enter into the construction of $\mathrm{C}$ in declaratives? The answer in short is none. To see this consider example (21) first. ${ }^{6}$

* Peter gives a damn about the environment. [XP even [Peter cares to the [minimal $]_{\mathrm{Foc}}$ degree about the environment] 
Example (21) is predicted to be ungrammatical whether NOD may enter into the construction of $\mathrm{C}$ or not. Relevant properties of the LF for (21) are shown in (22) (c.f. (15) above). The options for $\mathrm{C}$ are again the alternatives given in (18a-c). As before, choosing either (18a) or (18b) leads to contradictory presuppositions because either Non-triviality (7ii) or the Scalar Presupposition (7i) will be violated. This leaves value $3((18 \mathrm{c}))$ as the only non-contradictory value for $C: C=\left\{W-\cup \llbracket X P \rrbracket^{f}\right\}$. Although choosing value 3 ensures that the presuppositions of the sentence are consistent, the presuppositions now contradict the assertion, since (21), given value 3, presupposes that Peter doesn't care about the environment but asserts that he does care, albeit only to the minimal degree. This is shown in (23).

assert: $\mathrm{p}=$ that Peter cares to the minimal degree about the environment

presuppose: q=that Peter doesn't care about the environment $\&$ $\mathrm{p}$ is less likely than $\mathrm{q}$;

There is then no way to chose a value for $\mathrm{C}$ which leads to a consistent result, which explains why (21) is degraded. grammatical. $^{\dagger}$

Example (24) with the sketched LF in (25), is predicted to be

$\checkmark$ Peter doesn't give a damn about the environment.

[XP even [Peter does not care to the [minimal $]_{F o c}$ degree about the environment]]

From the literature on even we know that a theory which assumes (9) rather than (10), i.e. a theory without NOD, is capable of generating the relevant readings of (24). The only worry is whether including NOD in the construction of $\mathrm{C}$ leads to overgeneration. Since even in this case scopes above negation, NOD will be the following proposition: It is false that Peter doesn't care about the environment at all or that Peter cares to the environment to some small degree or $\ldots$ or that Peter cares about the environment to a large degree. In other words, NOD is the proposition that Peter cares to some degree about the environment. The inclusion of NOD in $\mathrm{C}$ entails in conjunction with (7iii), Truth of All Alternatives, that Peter cares about the environment. At the same time (24), asserts that Peter doesn't care about the environment at all. This contradiction makes any value for C which includes NOD unusable for examples like (24). Consequently, the availability of NOD in principle does not have any unwanted consequences for example (24) and negated declaratives in general.

The brief discussion in this subsection was meant to illustrate that the availability of NOD as a candidate for the inclusion in $\mathrm{C}$ does not lead to any unwanted predictions for declaratives. 


\subsection{Negated polar interrogatives}

I will now very briefly discuss negated polar interrogatives. Negated polar interrogatives like (26) are unproblematic for my account. They are not necessarily rhetorical questions. In the LF even takes scope above negation as shown in (27) (see the parallel declarative (24) with LF (25) and fn. 7).

(26) Doesn't John give a damn about the environment?

(27) $\left[\mathrm{Q}_{\text {polar }}\left[\mathrm{xP}\right.\right.$ even $\left[\right.$ Peter does not care to the $[\text { minimal }]_{\mathrm{Foc}}$ degree about the environment]]]

Such examples can be combined consistently with presuppositions that do not involve NOD. We saw this above in the discussion of the completely parallel example (24). As before these same presuppositions will be inherited by both members of the question set. Given the presuppositions that come with (24), (26) can be used as a regular interrogative. It presupposes that John doesn't care a lot about the environment and asks whether he cares to the minimal degree or not at all. As far as I can tell this is the interpretation the example actually has. Negated polar interrogatives are thus unproblematic.

\subsection{Minimizers in wh-interrogatives}

We now turn to example (2b) repeated here for convenience. The LF for this example is sketched in (28). Example (2b) again denotes a set of propositions. Ignoring presuppositions, this is the set in (29).

(2) b. Who gives a damn about the environment?

(28) $\left[\mathrm{Who}_{1} \mathrm{Q}_{\mathrm{wh}}\left[\right.\right.$ even $\left[\mathrm{t}_{1}\right.$ cares to the $[\text { minimal }]_{\mathrm{F}}$ degree about the environment]]]

(29) $\llbracket(2 b) \rrbracket=\left\{p_{<s, \triangleright} \mid \exists x p=\lambda w . x\right.$ cares about the environment to the minimal degree $\}$

$=\{$ that Peter cares about the environment to the minimal degree, that Mary cares about the environment to the minimal degree, that Frank cares about the environment to the minimal degree, ... $\}$

Each of the propositions in (29) comes with its own set of presuppositions. For the various values of $\mathrm{x}$ (Peter, Mary, Frank,...) these presuppositions are as in (30).

(30) (i) $\forall \mathrm{q}_{\mathrm{ss}, \mathrm{D}}[[\mathrm{q} \in \mathrm{C} \& \mathrm{q} \neq$ that $\mathrm{x}$ cares to the minimal degree about the environment] $\rightarrow \mathrm{q}>_{\text {likely }}$ that $\mathrm{x}$ cares to the minimal degree about the environment]

(ii) $\exists \mathrm{q}_{\mathrm{ks}, \triangleright}[\mathrm{q} \in \mathrm{C} \& \mathrm{q} \neq$ that $\mathrm{x}$ cares to the minimal degree about the environment]

(iii) $\forall \mathrm{q}_{\mathrm{ss}, \triangleright}[[\mathrm{q} \in \mathrm{C} \& \mathrm{q} \neq$ that $\mathrm{x}$ cares to the minimal degree about the environment] $\rightarrow \mathrm{q}(\mathrm{w})$ ] 
And as before we need to ask the question what values of $\mathrm{C}$ are possible, where the boundary condition from (10) only says $C \subseteq\left(\llbracket X P \rrbracket^{f} \cup\left\{\mathrm{W}-\cup \llbracket \mathrm{XP} \rrbracket^{\mathrm{f}}\right\}\right)$. Consider again the now familiar three types of values.

a. Value 1: $\mathrm{C}=\varnothing$ or $\mathrm{C}=\{\mathrm{p}\}$

b. Value 2: $\mathrm{C}=\{$ that $\mathrm{x}$ cares to the minimal degree about the environment, that $\mathrm{x}$ cares to a certain (small) degree about the environment, that $x$ cares to a large degree about the environment

c. Value 3: $\mathrm{C}=\{$ that $\mathrm{x}$ does not care about the environment; that $\mathrm{x}$ cares to the minimal degree about the environment $\}=$ $\left\{\mathrm{W}-\cup \llbracket \mathrm{XP} \rrbracket^{\mathrm{f}}, \mathrm{p}\right\}$

or $\mathrm{C}=\{$ that $\mathrm{x}$ does not care about the environment $\}=$ $\left\{\mathrm{W}-\cup \llbracket \mathrm{XP} \rrbracket^{\mathrm{f}}\right\}$

Value 1 ((31a)) is not a possible value for $\mathrm{C}$, because of (17ii), i.e. because any utterance of $(2 \mathrm{~b})$ presupposes that the set of alternatives is not trivial.

Value $2((31 b))$ is likewise not a possible value for $C$. Value 2 is impossible because of (17i), i.e. because of the scalar presupposition of even. To see this consider the following where again $\mathrm{p}$ stands for the proposition that $x$ cares to the minimal degree about the environment and $\mathrm{q}$ for one of the alternatives from $\mathrm{C}$, e.g. that $x$ cares to a large degree about the environment. $\mathrm{q}$ entails $\mathrm{p}(\mathrm{q} \rightarrow \mathrm{p}$, i.e. $\mathrm{q} \subseteq \mathrm{p}$ ) because caring a lot about the environment entails caring to the minimal degree. $p$ on the other hand does not entail $q(\neg[\mathrm{p} \rightarrow \mathrm{q}]$, or in other words $\mathrm{p} \nsubseteq \mathrm{q}$ ) because caring to the minimal degree about the environment does not entail caring to a large degree. In other words, $q$ asymmetrically entails $p$ $(q \subset \mathrm{p})$. From this it follows that $|\mathrm{q}|<|\mathrm{p}|$. If as in this case there are less worlds compatible with $\mathrm{q}$ than with $\mathrm{p}$, then $\mathrm{q}$ is less likely than $\mathrm{p}(\mathrm{q}<$ likely $\mathrm{p})$. But $(17 \mathrm{i})$ demands on the contrary that $\mathrm{q}>$ likely $\mathrm{p}$.

The same is true for all possible values of $\mathrm{C}$ which include propositions of the form that $x$ cares to degree $d$ about the environment, where $d$ is greater than the minimal degree.

Finally, value 3 is in principle possible. It is possible that NOD (that $x$ doesn't care about the environment at all) is more likely than $\mathrm{p}$ (that $x$ cares to the environment to the minimal degree) ((17i)). If $\mathrm{C}$ is assigned value $3, \mathrm{C}$ is nontrivial ((17ii)). And, according to (17iii) NOD must be true.

The fully fleshed out interpretation of example (2b) is given in (32).

$$
\llbracket(2 b) \rrbracket=\{
$$

assert: $\quad \mathrm{p}_{1}=$ that Peter cares about the environment to the minimal degree

presuppose: $\mathrm{q}_{1}=$ that Peter doesn't care about the environment $\mathrm{p}_{1}$ is less likely than $\mathrm{q}_{1}$, 
assert: $\quad \mathrm{p}_{2}=$ that Mary cares about the environment to the minimal degree

presuppose: $\mathrm{q}_{2}=$ that Mary doesn't care about the environment $\mathrm{p}_{2}$ is less likely than $\mathrm{q}_{2}$,

assert: $\quad \mathrm{p}_{3}=$ that Frank cares about the environment to the minimal degree

presuppose: $\mathrm{q}_{3}=$ that Frank doesn't care about the environment $\mathrm{p}_{3}$ is less likely than $\mathrm{q}_{3}$, $\ldots\}$

(32) amounts to saying that for every individual $x$ (the range for the variable $\mathrm{x}$ is determined by the contextual restriction on who), the proposition that $x$ does not care about the environment is accommodated. The question presupposes that for all relevant $\mathrm{x}, \mathrm{x}$ doesn't care about the environment. ${ }^{8}$ As in the case of the polar interrogative, this presuppositions accounts for the rhetorical effect. What is intuitively felt as the content of the rhetorical question is never asserted, it is a presupposition that is automatically accommodated.

We have seen in this section how the lexical entry of even in (7) together with the assumption that NOD can be used in the construction of the contextual restriction on even $((10))$ account in a natural way for the emergence of the rhetorical effect.

\section{Additional evidence for including NOD in the construction of C}

Consider examples (33) through (36). (A version of (34) was first pointed out to me by Yael Sharvit (p.c.).)

(33) $\checkmark$ John would like to know which of his friends give a damn about the environment and which don't.

(34) \#John believes that people are more likely to care about the environment than not to care about it, and he would (actually) like to know which of his friends give a damn about the environment and which don't.

$\checkmark$ John believes that people are more likely not to care about the environment than to care about it, and he would (actually) like to know which of his friends give a damn about the environment and which don't.

$\checkmark$ John believes that people are more/less likely to care about the environment than not to care about it, and he would like to know which of his friends care about the environment and which don't.

Examples (33) and (35) show that embedded questions with Minimizers are in principle acceptable. ${ }^{9}$ However, in the context provided in (34), the same question is decidedly odd. The oddness of (34) must be attributed to the interaction of the Minimizer in the question with the context. It is not in principle odd to ask the question intended in (34), as (36) shows. 
The oddness of (34) must somehow be attributed to the presence of a minimzer in (34) together with the particular context given there. When the context is changed the oddness disappears as (35) shows.

The explanation why example (34) is degraded but (35) isn't is quite straightforward. The first conjunct question in (33) through (35) is in relevant respects identical to (2b). We saw above that (2b) presupposes for all relevant individuals that caring about the environment is less likely than not caring. This presupposition is explicitly denied in (34) but not in (33) and (35). This accounts for why (34) but not (33) and (35) is odd. Without assuming that the likelihood of NOD (that the relevant people are less likely to care about the environment than not to care) enters into the interpretation of questions with Minimizers, the different status of (34) and (35) remains mysterious. This casts some doubt on accounts of the rhetorical effect that are not based on the availability of NOD (e.g. Guerzoni 2002; Han 2002).

I now briefly turn to the open issue of the lack of a rhetorical effect in (33). According to the discussion of (2b) above, the first conjunct question in (33) through (35) should have the presuppositions in (37).

(37) For the various values of $x$ (Peter, Mary, Frank,...):

(i) $\forall \mathrm{q}_{\mathrm{ks}, \mathrm{D}}[[\mathrm{q} \in \mathrm{C} \& \mathrm{q} \neq$ that $\mathrm{x}$ cares to the minimal degree about the environment] $\rightarrow \mathrm{q}>$ likely that $\mathrm{x}$ cares to the minimal degree about the environment]

(ii) $\exists \mathrm{q}_{\mathrm{s}, \mathrm{D}}[\mathrm{q} \in \mathrm{C} \& \mathrm{q} \neq$ that $\mathrm{x}$ cares to the minimal degree about the environment]

(iii) $\forall \mathrm{q}_{\mathrm{ks}, \mathrm{\triangleright}}[[\mathrm{q} \in \mathrm{C} \& \mathrm{q} \neq$ that $\mathrm{x}$ cares to the minimal degree about the environment] $\rightarrow \mathrm{q}(\mathrm{w})]$

The only value for $\mathrm{C}$ that yields consistent presuppositions is value 3 (i.e. (31c)) above. The rhetorical effect arises from this forced choice of a value for $\mathrm{C}$ because of presupposition (37iii) - Truth of all alternatives. It follows from (37iii) and value 3 for $\mathrm{C}$ that none of the relevant individuals care to the minimal degree about the environment. The absence of the rhetorical effect in (33) through (35) then indicates that presupposition (iii) can be and is canceled in these contexts. The actual presuppositions of (33) through (35) are only those in (38).

(38) For the various values of $x$ (Peter, Mary, Frank,...):

(i) $\forall \mathrm{q}_{\mathrm{ks}, \mathrm{D}}[[\mathrm{q} \in \mathrm{C} \& \mathrm{q} \neq$ that $\mathrm{x}$ cares to the minimal degree about the environment] $\rightarrow \mathrm{q}>$ likely that $\mathrm{x}$ cares to the minimal degree about the environment]

(ii) $\exists \mathrm{q}_{\mathrm{ss}, \mathrm{\downarrow}}[\mathrm{q} \in \mathrm{C} \& \mathrm{q} \neq$ that $\mathrm{x}$ cares to the minimal degree about the environment]

Note that assuming (38) does not jeopardize our explanation for the contrast between (34) and (35). The presupposition crucial in the explanation of the contrast between (34) and (35) was not the cancelled presupposition (37iii) but rather the scalarity presupposition (37i), which is not canceled (38i). ${ }^{10}$ 
The rhetorical effect can be absent in embedded interrogatives with Minimizers more generally. This amounts to saying that under contextual pressure the Truth of All Alternatives presupposition of even ((7iii)) can be canceled. We know, of course, that presuppositions can sometimes be canceled. Thus the existence presupposition attributed to the definite article on Strawson's view of definite descriptions is canceled in the following exchange. A: Is the king of France bald? - B: No, the king of France isn't bald. France doesn't have a king.

Consider now example (39).

(39) Context: My friend Kirsten, who has a bad back, has recently moved while I was away. I was hoping that some other people would help her move the heavy boxes. People are giving evasive answers to the question how many boxes they carried.

In mounting desperation I ask:

Who of you even lifted a finger to help Kirsten?

In example (39) the relevant value for the restriction on even again contains NOD: that $x$ didn't do anything to help Kirsten. In the particular context, the speaker is not in a position to make this presupposition since he wasn't present. He doesn't know NOD and his interlocuters know that he doesn't know. The presupposition that NOD be true is then canceled and the question can be interpreted as a non-rhetorical, real question. The same happens in (33) through (35).

We have seen in this section that the contrast between (34) and (35) falls out from the present account, where NOD may enter into the construction of the contextual restriction on even. In fact, an account of the contrast between these examples that does not involve NOD at all seems difficult. Other accounts (Guerzoni 2002; Han 2002) do not invoke NOD and hence make no comparable prediction. This can be taken as an argument for the present account.

\section{Conclusion}

I have provided a novel account of the rhetorical effect of Minimizers in Interrogatives. Minimizers were analyzed as semantically equivalent to scalar endpoints + even (Heim 1984).

The account rests crucially on the assumption that the contextual restriction on even may contain a member not included in the focus semantic value of the LF-sister of even, the negation of its disjunction.

(10) Let $\alpha$ be the sister of even at LF, $\llbracket \alpha \rrbracket f$ be the focus semantic value of $\alpha$, $\mathrm{C}$ the contextual restriction on even, and $W$ the set of possible worlds, then $C \subseteq(\llbracket \alpha \rrbracket f \cup\{\mathbf{W}-\cup[\alpha] \mathbf{f}\})$. 
This assumption not only accounts for the rhetorical effect, it appears to be a necessary ingredient of any account of the contrast between examples like (34) and (35). The assumption that W- $\cup \mathrm{P}$ (NOD) plays a role is independently justified for interrogatives and focus constructions as shown in section 3.

\section{Endnotes}

This paper grew out of my second general examinations paper. I owe tremendous thanks to my committee Sigrid Beck, Yael Sharvit, and Howard Lasnik. Outside of my committee I would like to thank Elena Guerzoni and Luisa Martí. I would also like to thank the audiences at the Fourth UConn-UMass-MIT Semantics Workshop, at the NELS 33 poster session, at the Penn Linguistic Colloquium 27, and, of course, at SALT XIII. All errors and shortcomings are my own.

${ }^{1}$ Note that the research program aimed at eliminating [+/- NPI] as a primitive, a diacritic, from the theory forces us to adopt the scope theory of even (Karttunen and Peters 1979; Wilkinson 1996). Rooth's (1985) competing ambiguity theory of even distinguishes the two lexical entries of even with the diacritic [+/-NPI]. The ambiguity theory must for that reason be rejected.

${ }^{2}$ Notice that the truth of (7iii) follows from the assertion (5iv) iff the alternatives form a true scale. The crucial property of example (6) is that the different alternatives do not form a scale a priori. There is no necessary link between solving problem \#n and solving problem \#m.

3 The Roothian way of implementing association with focus is chosen for concreteness only. Nothing hinges on it as far as I can see. In particular, if the set of focal alternatives is not determined syntactically as the LF sister of even but is given pragmatically as a question under discussion (see for example Martí 2003; Roberts 1998), C will have to be a subset of that question and the modification in (10) will have to be made to the question under discussion. Given the discussion in section 3.1 below, this would be a natural move.

${ }^{4}$ If we assume that the question in (11) carries the existential presupposition that somebody came, then (11b) but not (11c) is predicted to be odd independently of a ban against quantified answers in the question set, because (11b) is totally uninformative and simply asserts what is already presupposed.

${ }^{5}$ If $\mathrm{p}$ and $\mathrm{q}$ are finite sets, the step from $\mathrm{q} \subset \mathrm{p}$ to $|\mathrm{q}|<|\mathrm{p}|$ is trivial, but not if they are infinite. I will ignore the issue here.

${ }^{6}$ I will only discuss the two simplest cases, (21) and (24), here. For discussion of other cases see Abels 2002.

${ }^{7}$ It is noted in the literature (e.g. Lahiri 1998; Wilkinson 1996) that even must scope above negation in negated monoclausal examples. The reasons for this are unclear.

${ }^{8}$ The situation is actually a little more complicated. In polar interrogatives it seems to be true that the presuppositions of the interrogative can simply be accommodated; thus, consider (i) in a context that does not entail that Peter 
smoked at some point. Example (ii) on the other hand does not presuppose that all addressees smoked at some point.

(i) Has Peter quit smoking?

(ii) Which of you have quit smoking?

The question is where the line is between accommodating the presuppositions for all relevant individuals (as seems to be necessary to derive the rhetorical effect) and accommodating only an existentially quantified version according to which there is at least one individual that fulfills the presuppositions (which seems to be sufficient for examples like (ii)). I do not at present have an answer to this question.

${ }^{9}$ Notice that the rhetorical effect is absent in example (33). I turn to this issue in a moment.

10 The fact that the Truth of All Alternatives presupposition is cancelable is interesting in light of the discussion of that presupposition in section (3) of this paper. Further care in formulating the presupposition (see Kay 1990) might shed light on the issue why this presupposition can be canceled but others cannot.

\section{References}

Abels, Klaus. 2002. Revolution \#9 - Not by the Beatles. Ms. University of Connecticut, Storrs

Chierchia, Gennaro. 2000. Scalar Implicatures and Polarity Items. Paper presented at 31 Conference of the North East Linguistics Society, Georgetown University, Washington, DC.

Guerzoni, Elena. 2002. Even NPIs in Questions. Paper presented at NELS 32, NYU.

Hamblin, C. L. 1973. Questions in Montague English. Foundations of Language 10:41-53.

Han, Chung-Hye. 2002. Interpreting interrogatives as rhetorical questions. Lingua 112:201-229.

Han, Chung-Hye, and Laura Siegel. 1996. Syntactic and Semantic Conditions on NPI Licensing in Questions. In Proceedings of the Fifteenth West Coast Conference on Formal Linguistics, 177-191. Stanford: CSLI.

Heim, Irene. 1984. A Note on Negative Polarity and Downward Entailingness. In NELS 14, eds. C Jones and P Sells, 98-107. Amherst, MA.: GLSA.

Kadmon, Nirit, and Fred Landman. 1993. Any. Linguistics and Philosophy 16:353-422.

Karttunen, Lauri. 1977. Syntax and semantics of questions. Linguistics and Philosophy 1:3-44.

Karttunen, Lauri, and Stanley Peters. 1979. Conventional Implicature. In Syntax and Semantics 11: Presuppositions, eds. Choon-Kyu Oh and David A. Dinneen, 1-56. New York, San Francisco, London: Academic Press.

Kay, Paul. 1990. Even. Linguistics and Philosophy 13:59-111. 
Klima, Edward S. 1964. Negation in English. In The structure of language: Readings in the philosophy of language, eds. Jerry A. Fodor and Jerrold J. Katz, 246-323. Englewood Cliffs, N. J.: Prentice-Hall.

Krifka, Manfred. 1994. The semantics and pragmatics of weak and strong polarity items. In Proceedings from Semantics and Linguistic Theory IV, eds. Mandy Harvey and Lynn Santelmann, 195-219. Ithaca, NY: Cornell University.

-. 1995. The semantics and pragmatics of polarity items. Linguistic Analysis 25:209-257.

Ladusaw, William. 1980. Polarity Sensitivity as Inherent Scope Relations. New York: Garland.

Lahiri, Utpal. 1998. Focus and negative polarity in Hindi. Natural Language Semantics 6:57-123.

Lee, Young-Suk, and Laurence Horn. 1995. Any as Indefinite plus Even. Ms. Yale University, New Haven, CT.C:LMy Documents\Aufsaetze von anderenlLee and Horn 1995 Any as indefinite + even.doc

Linebarger, Marcia. 1980. The grammar of negative polarity. Doctoral dissertation. MIT, Cambridge, MA.

Martí, Luisa. 2003. Contextual Variables. Doctoral Dissertation. Univeristy of Connecticut, Storrs.

Progovac, Ljiljana. 1993. Negative Polarity: Entailment and Binding. Linguistics and Philosophy 16:149-180.

Roberts, Craige. 1998. Information Structure in Discourse: Towards an Integrated Formal Theory of Pragmatics. Ms. Semantics Archive.http://semanticsarchive.net/Archive/WYzOTRkO/InfoStructure.p df

Rooth, Mats Edward. 1985. Association with Focus. Ph.D. thesis. University of Massachusetts, Amherst, MA.

- 1992. A theory of focus interpretation. Natural Language Semantics 1:75-116. van Rooy, Robert. 2002. Negative Polarity Items in Questions: Strength as Relevance. Ms. ILLC/University of Amsterdam

von Fintel, Kai. 1999. NPI Licensing, Strawson Entailment, and Context Dependency. Journal of Semantics 16:97-148.

Wilkinson, Karina. 1996. The Scope of Even. Natural Language Semantics 4:193-215. 